\title{
Prediction of sliding distance of seismic landslides in Loess Plateau, China
}

\author{
Wang Lanmin ${ }^{\text {i) }}$, Wang Nai ${ }^{\text {ii) }}$ and Wang Qian ${ }^{\text {iii) }}$ \\ i) Professor, Lanzhou Institute of Seismology, China Earthquake Administration, 450, Donggang West Street, Lanzhou 730000, China. \\ ii) Ph.D Student, Lanzhou Institute of Seismology, CEA, 450, Donggang West Street, Lanzhou 730000, China Research Institute of \\ Petroleum Exploration \& Development, Beijing 310058, China;. \\ iii) Ph.D Student, Lanzhou Institute of Seismology, CEA, 450, Donggang West Street, Lanzhou 730000, China.
}

\begin{abstract}
Earthquake induced landslides were one of major causes for a large number of deaths and huge economic loss in the Loess Plateau. In order to evaluate the influencing area of seismic landslides, we presented a method of predicting sliding distance of seismic landslides in Loess Plateau by means of fuzzy information model based on 93 cases data of seismic loess landslides. Firstly, the types, characteristics, and influencing factors of seismic landslides in Loess Plateau were studied based on field investigation, back analysis and laboratory tests. Secondly, Morgenstern-Price method was used for calculating the seismic stability of loess slopes. The relationships between safe factor and influencing factors were established, which include seismic intensity, relative altitude, slope angle, unit weight, internal cohesion, internal friction angle. Furthermore, the factors of influencing sliding distance of landslides were figured out. Thirdly, a fuzzy information matrix was established based on 93 loess seismic landslides caused by South Tianshui 8.0 earthquake in 1654, Tong Wei 7.5 earthquake in 1718, Haiyuan 8.5 earthquake in 1920 and Gulang 8.0 earthquake in 1927. And then a fuzzy information model was developed for calculating sliding distance and influencing area of seismic loess landslides. Fourthly, the influencing areas of 22 potential landslides in Tianshui city were respectively predicted. The predicted results shown that the method presented in the paper is more accurate for seismic loess landslides, comparing with other methods.
\end{abstract}

Keywords: sliding distance, seismic landslide, prediction, loess plateau

\section{INTRODUCTION}

The Loess Plateau with an area of $4.4 * 10^{5} \mathrm{~km}$ is an earthquake prone region, where earthquakes occurred for 7 times with magnitude of Ms $>=8,22$ times with Ms7-7.9, 67 times with Ms6-6.9, and 258 times with Ms5-5.9 in history. These earthquakes killed more than 1.4 million people in Loess plateau. Earthquake induced landslides were one of major causes for a large number of deaths and huge economic loss ${ }^{[1]}$. Countless loess seismic landslides have occurred during past hundreds of years. The landslides' influence area of Tianshui earthquake in 1654 was about $1000 \mathrm{~km}^{2}$. There were 59 seismic landslides more than 500 meters. The landslides' influence area of Tongwei earthquake in 1718 was about $3500 \mathrm{~km}^{2}$. There were 337 seismic landslides more than 500 meters. The landslides' influence area of Haiyuan earthquake in 1920 was about $50000 \mathrm{~km}^{2}$. There were 59 seismic landslides more than 657 meters ${ }^{[2]}$.

Theory of fuzzy information was put forward by the famous American cybernetician Chad in his pioneering paper to describe the theoretical system of fuzzy phenomena. In this paper, we presented a method of predicting sliding distance of seismic landslides in Loess Plateau by means of fuzzy information model based on 93 cases data of seismic loess landslides.

\section{LANDSLIDES TYPES}

By studying on 104 seismic landslides of valley city, statistical analysis results show that types of landside in the valley city of loess areas are classified as loess landslides, loess-bedrock interface landslides, loess-bedrock landslides and loess-gravel-bedrock landslides ${ }^{[3-4]}$.

\subsection{Loess Landslide}

The sketch of seismic landslides in loess is shown in figure 1 . The landslides are usually formed in the thick loess layer with steep slope angle. Under the effect of earthquakes, the seismic inertial force and slope angle increases instantly and generates destruction of loess structure. Landslides appeared because of seismic effect when the soil mass began to fall. Yet if the displacement of soil mass is too little to form landslide, fissure of soil mass appears in the behind of the slope. The type of landslides caused by another earthquake or 
precipitation still belongs to loess landslides. Results show that the loess landslides have such characteristic as steep slope angle, high slip velocity and long sliding distance.

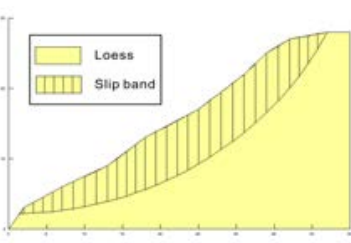

(a)

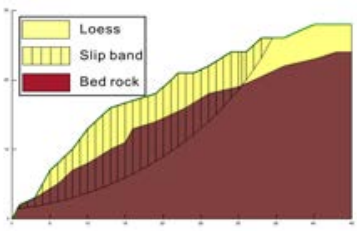

(c)

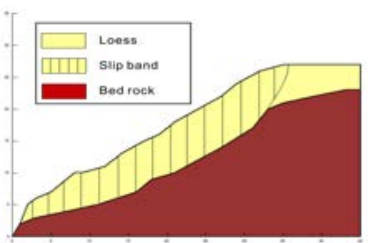

(b)

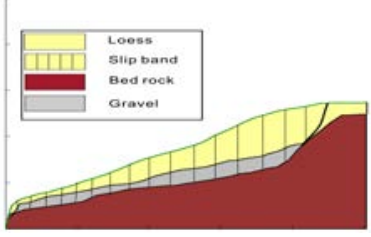

(d)
Fig.1 Seismic Loess Landslides Figure

\subsection{Loess-bedrock interface Landslide}

The sketch of loess-bedrock interface landslide is shown in figure 2. The upper layer of the landslides is loess layer and the rest is bedrock layer. Due to the difference of permeability of loess and bedrock layers, the shearing strength of soil which located in the interface is induced by the external factors. Landslides take place when the frictional resistance is less than the upper soil mass weight and seismic inertial force. This type of landslides has gentle slope angle and small scale.

\subsection{Loess-bedrock Landslide}

Loess-bedrock landslide is composed by loess and bedrock, shown in figure 3. Due to the effect of earthquakes, soil mass slips along the weak surface slowly and the extension fractures appear in the upper soil body of slope. When the frictional resistance is less than the slip mass weight and seismic inertial force, landslides occurred.

\subsection{Loess-gravel-bedrock Landslide}

The bedrock and gravel between the loess and bedrock are obvious at the end of the slope. The slope is mainly distributed in valley terrace of Middle East Wuxiaoling and west of LiuPan Mountain [5-6]. Since Tertiary red layer has certain waterproof function, the weak side is easy to make the soil sliding along it.

The investigation on 147 seismic landslides shown that Loess landslide occupies $63.3 \%$ of the total number of landslides, loess-bedrock interface landslide 6\%, loess-bedrock landslide $22.5 \%$, and loess-gravelbedrock landslide $8.2 \%$.

\section{SAFE FACTORS}

As an example, modeling and seismic hazard analysis evaluation for the slopes in Tianshui city is given. Tianshui is located in the north of Tibet Plateau seismic belt. Hence, seismic activities is frequently and high intensity. Several huge earthquakes have caused severe disasters. The seismic hazard analysis of the dangerous slope located in the Tianshui town is given and expected to be helpful for the landslides hazard survey. The range of investigation is from Qinzhou District to Beidao District.

The stability of the slope is quantitative evaluated with the safety coefficient. Based on the analysis of the limit equilibrium principle, this paper used Morgenstern-Price method to analysis the stability

Static equilibrium equation:

$F_{\mathrm{m}}=\frac{\sum\left[\mathrm{c}^{\prime} \beta \mathrm{R}+(\mathrm{N}-\mu \beta) \mathrm{R} \tan \phi^{\prime}\right]}{\sum W x-\sum N f \pm D \mathrm{~d}}$

Moment equilibrium equation:

$F_{f}=\frac{\sum\left[\mathrm{c}^{\prime} \beta \cos \alpha+(\mathrm{N}-\mu \beta) \tan \phi^{\prime} \cos \alpha\right]}{\sum N \sin \alpha-\mathrm{D} \cos \omega}$

Slice normal force equation:

$$
N=\frac{W+\left(X_{R}-X_{L}\right)-\frac{c^{\prime} \beta \sin \alpha+u \beta \sin \alpha \tan \phi^{\prime}}{F}}{\cos \alpha+\frac{\sin \alpha \tan \phi^{\prime}}{F}}
$$

Iterative formula:

$$
X=\lambda * \mathrm{f}(\mathrm{x}) * \mathrm{E}
$$

In the equations, $\mathrm{X}$ means interaction of shear force of slices, $E$ means the normal force between the slices, $\mathrm{W}$ is the soil slice weight, $\alpha$ is the dip Angle of base area, the pore water pressure between slices is ui, internal friction angle of slices is $\varphi$ ', c' means cohesion and the factor of safety is F. As shown in figure.7, the factor of safety could be calculated by the Eq. 1, Eq. 2, Eq. 3 and Eq. 4.

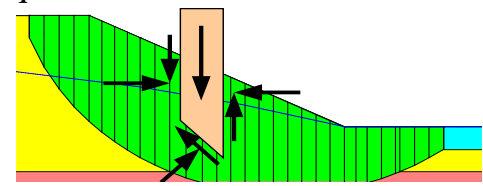

Fig.2 interaction of slice

According to Seismic Design Code for Construction and Map of Seismic Ground Motion Parameters Zoning of China, the buildings in Tianshui must follow 8-class intensity fortification which the designed seismic acceleration is $0.30 \mathrm{~g}$. In order to evaluate the seismic hazard of slope fully detailed, the range of designed seismic acceleration is amplified from $0.05 \mathrm{~g}$ to $0.40 \mathrm{~g}$. That means the standard is amplified to 9 class intensity. As is shown in table 5, with rising of the loading seismic acceleration, the factor of safety of slope models is decreased. However, the reducing trend is different considering the difference of soil physical parameters and slope angle. 
Table 1 Slope Stability with Different Seismic Acceleration (S for Safe and D for danger)

\begin{tabular}{cccccc}
\hline \multirow{2}{*}{ Models } & \multirow{2}{*}{$\begin{array}{c}\text { Geographic } \\
\text { coordinates }\end{array}$} & \multicolumn{4}{c}{ FOS with different seismic } \\
& & acceleration \\
\cline { 3 - 6 } QZ-1 & N34.56 E105.68 & S & D & D.30 & 0.40 \\
\hline QZ-2 & N34.56 E105.68 & S & D & D & D \\
\hline QZ-3 & N34.56 E105.68 & S & S & D & D \\
\hline QZ-4 & N34.56 E105.68 & S & S & D & D \\
\hline QZ-5 & N34.56 E105.68 & S & S & D & D \\
\hline QZ-6 & N34.56 E105.68 & S & S & D & D \\
\hline QZ-7 & N34.56 E105.68 & S & D & D & D \\
\hline QZ-8 & N34.56 E105.68 & S & S & D & D \\
\hline QZ-9 & N34.56 E105.68 & S & S & D & D \\
\hline QZ-10 & N34.56 E105.68 & S & D & D & D \\
\hline MJ-1 & N34.57 E105.91 & S & S & D & D \\
\hline MJ-2 & N34.58 E105.90 & S & D & D & D \\
\hline MJ-3 & N34.58 E105.88 & S & D & D & D \\
\hline MJ-4 & N34.57 E105.88 & S & D & D & D \\
\hline MJ-5 & N34.58 E105.87 & S & S & D & D \\
\hline MJ-6 & N34.53 E105.87 & S & S & S & D \\
\hline MJ-7 & N34.53 E105.87 & S & D & D & D \\
\hline MJ-8 & N34.55 E105.87 & S & S & S & D \\
\hline MJ-9 & N34.55 E105.87 & S & S & D & D \\
\hline MJ-ST-1 & N34.55 E105.77 & S & D & D & D \\
\hline MJ-ST-2 & N34.56 E105.97 & S & S & D & D \\
\hline MJ-ST-3 & N34.56 E105.98 & S & D & D & D \\
\hline
\end{tabular}

\section{INFLUENCE FACTORS}

Intensity is a standard to evaluate the degree of seismic damage ${ }^{[7-8]}$. In different intensity area, the scale and area of loess landslide are different. In loess plateau, the level of intensity that could induce landslide is low. Gangu earthquake (Ms=5) in 1962 and Xiji earthquake $(\mathrm{Ms}=5.4)$ in 1970 still led to lots of landslides. According to the figure, loess landslide occurs when intensity reaches to VI degree. Numerous landslides appear when intensity is above IX degree.

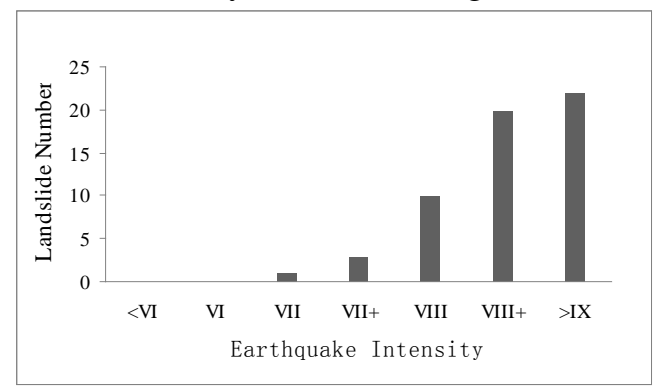

Fig. 3 Distribution of landslide number under the different seismic intensity

Relative altitude of landslide presents the change of surface and potential energy different. It will affect the frequency of landslide. The seismic landslide is caused by the internal and external factors. A large number of landslides are easy to slide at the same moment when an intense seismic energy breaks the balance. So the higher relative altitude produces more landslides. However, when relative altitude ranges from 50 to 250 meters, the landslides occur most frequently.

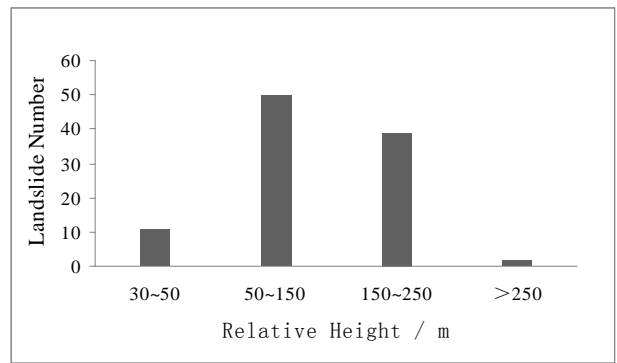

Fig. 4 Distribution of landslide number under the different relative altitude

The slope angle is an important internal factor of landslide. It reflects the possibility of the soil sliding. The angle determined the geometry of the slope. Even the increase of angle will induce landslide easily, angle of the seismic landslides is mainly distributed about $10^{\circ} \sim 25^{\circ}$ because of the limit of other factors.

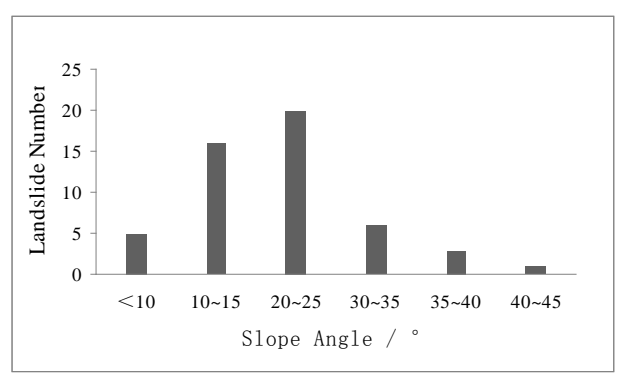

Fig. 5 Distribution of landslide number under the different slope angle

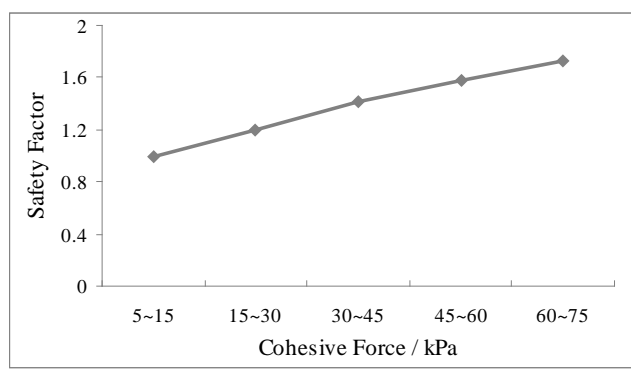

Fig. 6 Distribution of slope safe factor under the different internal cohesion

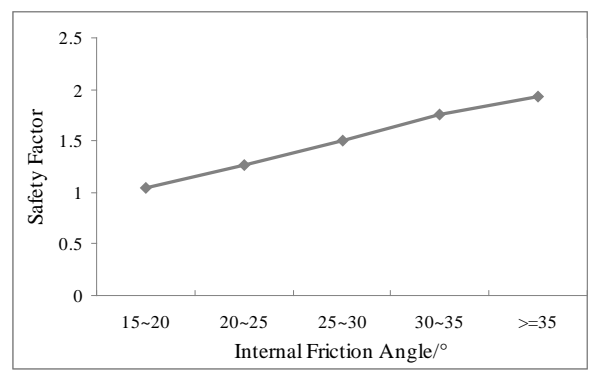

Fig. 7 Distribution of slope safe factor under the different internal friction angle

The physical factors which affect the slope stability include internal cohesion, internal friction angel and unit weight. Through the numerical model, we analyzed 
the regularity of the factor with another two factors fixed. In figure 7-9, it presented the trending that safe factor rises with increase of the internal cohesion and internal friction angel, and drops with decrease of the unit weigh.

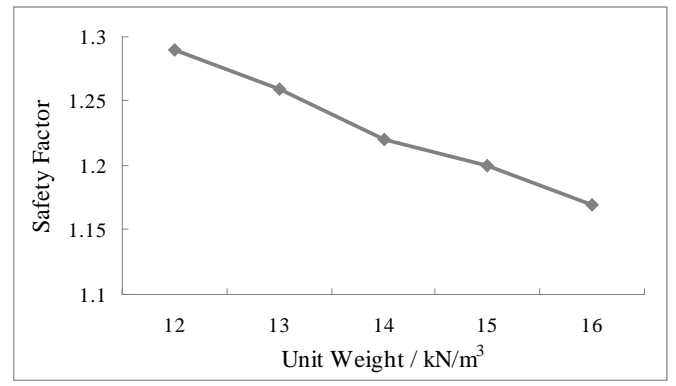

Fig. 8 Distribution of slope safe factor under the different unit weight

\section{METHOD}

This paper studied the sliding distance of seismic loess landslide. Therefore we defined distance from the rear of the sliding body to the furthest sliding place. As shown in the figure below, $\mathrm{L}$ means sliding distance.

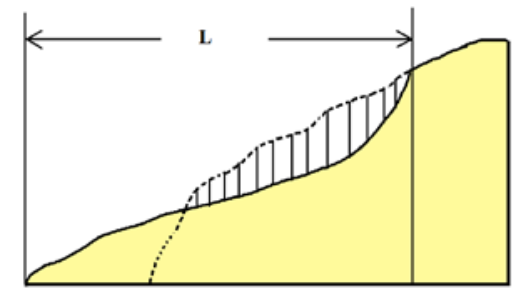

Fig.9 Loess seismic landslide distance

The fuzzy information method is used to calculate the distance ${ }^{[9]}$ :

We set $X$ as the independent variable domain or reason domain, $\mathrm{Y}$ as the dependent variable domain or consequence domain. In practical approximate reasoning model, a theory of domain is always represented by a finite number of discrete points.

$\mathrm{X}=\left\{\mathrm{x}_{1}, \mathrm{X}_{2}, \ldots, \mathrm{X}_{\mathrm{n}}\right\}$

$\mathrm{Y}=\left\{\mathrm{y}_{1}, \mathrm{y}_{2}, \ldots, \mathrm{y}_{\mathrm{n}}\right\}$

$A_{0}$ is observing events, and $X_{0}$ is reason, $Y_{0}$ is result, then $A_{0}=A_{0}\left(X_{0}, Y_{0}\right\}$. Set $R$ to describe $A$ Event, and to depict the reason causal laws. Results $\mathrm{X}$ and $\mathrm{Y}$ are:

$\mathrm{R}=\mathrm{R}(\mathrm{A})$

Therefore, when the $\mathrm{X}_{0}$ is known, we can figure out $\mathrm{Y}_{0}$ with appropriate approximate reasoning law “|”.

$$
\mathrm{Y}_{0}=\mathrm{X}_{0} \mid \mathrm{R}_{0}
$$

\section{EXAMPLE}

Using the fuzzy information optimization processing model, we have made a prediction of seismic landslide hazard distance for the Tianshui.

The collecting data shows that 95\% slip distance L range is $40-1500 \mathrm{~m}$. Relative altitude $H$ range is $20-240 \mathrm{~m}$. Average slope Angle $\alpha$ range is $7^{\circ}-70^{\circ}$, intensity $M$ range is 6-9. In accordance with the fuzzy information processing theory, the data domain is shown as follows:

$\mathrm{VL}=\{\mathrm{L} 1, \mathrm{~L} 2, \mathrm{~L} 3 \ldots \mathrm{L} 8\}=\{40,140,240,340,440,540,64$

$0,740,840,940,1040,1140,1240,1340,1440,1540\}$ $\mu \mathrm{H}=\{\mathrm{H} 1, \mathrm{H} 2, \mathrm{H} 3 \ldots \mathrm{H} 8\}=\{20,40,60,80,100,120,140,1$

$60,180,200,220,240\}$

\}

$\mu \alpha=\{\alpha 1, \alpha 2, \alpha 3 \ldots \alpha 7\}=\{7,14,21,28,35,42,49,56,63,70$

9\}

$\mu \mathrm{M}=\{\mathrm{M} 1, \quad \mathrm{M} 2, \quad \mathrm{M} 3 \ldots \mathrm{M} 6\}=\{6,7,7.5,8,8.5$,

The VL domain is the earthquake landslide slip distance, $\mu \mathrm{H} 、 \mu \alpha$ and $\mu \mathrm{M}$ are respectively relative latitude domain, average slope angle domain and intensity domain. According to the two dimensional normal information diffusion equation of $\mathrm{VL}$ and $\mu \mathrm{H}$, VL and $\mu \alpha$, VL and $\mu$ M, fuzzy relationship matrix was established. $\mathrm{M}$ is sample number, $\mathrm{m}=93$.Through two-dimensional normal information diffusion formula can be obtained respectively QHL, Q $\alpha \mathrm{L}$ and QML original information distribution matrix. The fuzzy information of the slip matrix RHL, R $\alpha \mathrm{L}$ and RML calculated by regularization processing could predicate the seismic loess landslide distance through fuzzy approximate reasoning formula $\mathrm{Y}=\mathrm{X} \mid \mathrm{R}$. $\mathrm{X}$ in landslide data to evaluate distribution formula is based on the information of one dimension processed data. According to the formula we can get reason domain $\mathrm{X}_{\mathrm{OH}}, \mathrm{X}_{\mathrm{O} \alpha}$ and $\mathrm{X}_{\mathrm{OM}}$.

According to the two dimension normal information formula as follow, we can calculate the $\mathrm{Q}_{\mathrm{ML}}$.

$f m(\mu, v)=\frac{1}{2 \pi m h^{2}} \sum_{j=1}^{m} \exp \left[-\frac{\left(\mu^{\prime}-\mu_{j}^{\prime}\right)^{2}+\left(v^{\prime}-v_{j}^{\prime}\right)^{2}}{2 h^{2}}\right]$

$\mu^{\prime}=\frac{\mu-a_{1}}{b_{1}-a_{1}}, \quad v^{\prime}=\frac{v-a_{2}}{b_{2}-a_{2}}$

$\mu_{j}^{\prime}=\frac{\mu_{j}-a_{1}}{b_{1}-a_{1}}, \quad v_{j}^{\prime}=\frac{v_{j}-a_{2}}{b_{2}-a_{2}}$

$a_{1}=\min _{1 \leq \mathrm{j} \leq m\left\{\mu_{j}\right\}}, \quad a_{2}=\min _{1 \leq \mathrm{j} \leq m\left\{v_{j}\right\}}$

$b_{1}=\max _{1 \leq j \leq m\left\{\mu_{j}\right\}}, b_{2}=\max _{1 \leq j \leq m\left\{v_{j}\right\}}$

$h=\frac{1.4208}{m-1}$

After normalization, the fuzzy information matrix $\mathrm{R}_{\mathrm{ML}}$ is given.

Through the fuzzy information formula $Y=X \mid R$, the reason domain $\mathrm{X}_{\mathrm{OM}}$ and possibility distribution $\mathrm{Y}_{\mathrm{ML}}$ are calculated.

According to the result, 22 landslides slip distance in Tianshui is shown as follow:

Analysis result shows that when the seismic intensity is greater than 8 degrees, the slopes measured in Tianshui city would produce the slide. Distance is 
ranging from 20 to $150 \mathrm{~m}$. The low speed slow slope should be paid more attention because the distance was calculated longer than other landslides. It meets the low Angle landslide characteristics of slow sliding speed, further distance and larger hazard area.

Table 2 Orginal Information Distribution QML

\begin{tabular}{|c|c|c|c|c|c|}
\hline 0.00 & 0.00 & 0.00 & 21.57 & 0.61 & 0.01 \\
\hline 0.00 & 21.67 & 3.80 & 45.89 & 20.33 & 5.75 \\
\hline 0.61 & 6.72 & 9.02 & 53.48 & 1.55 & 1.49 \\
\hline 7.12 & 4.67 & 7.99 & 11.25 & 6.13 & 0.21 \\
\hline 0.00 & 13.99 & 6.92 & 17.28 & 8.48 & 6.71 \\
\hline 6.50 & 6.33 & 1.49 & 11.63 & 7.82 & 1.49 \\
\hline 0.00 & 0.00 & 2.96 & 11.64 & 13.68 & 0.00 \\
\hline 0.00 & 0.00 & 0.06 & 4.72 & 1.49 & 0.00 \\
\hline 6.50 & 0.00 & 0.00 & 8.06 & 0.21 & 0.00 \\
\hline 0.21 & 0.00 & 0.00 & 0.61 & 0.00 & 0.00 \\
\hline 1.49 & 0.00 & 0.00 & 0.00 & 0.00 & 0.00 \\
\hline 0.00 & 0.00 & 0.00 & 0.00 & 0.00 & 0.00 \\
\hline 0.00 & 0.00 & 6.50 & 0.00 & 0.00 & 0.00 \\
\hline 0.00 & 0.00 & 0.00 & 0.00 & 0.00 & 0.00 \\
\hline 0.00 & 0.00 & 0.00 & 0.21 & 0.00 & 0.00 \\
\hline 0.00 & 0.00 & 0.00 & 1.49 & 0.00 & 0.00 \\
\hline
\end{tabular}

Table 3 Fuzzy Information Matrix RML

\begin{tabular}{|l|l|l|l|l|l|l|l|}
\hline 0.00 & 0.00 & 0.09 & 1.00 & 0.00 & 0.91 & 0.00 & 0.00 \\
\hline 0.00 & 1.00 & 0.31 & 0.22 & 0.65 & 0.29 & 0.00 & 0.00 \\
\hline 0.00 & 0.42 & 1.00 & 0.89 & 0.77 & 0.17 & 0.33 & 0.01 \\
\hline 0.40 & 0.86 & 1.00 & 0.21 & 0.32 & 0.22 & 0.22 & 0.09 \\
\hline 0.03 & 1.00 & 0.08 & 0.30 & 0.42 & 0.38 & 0.67 & 0.07 \\
\hline 0.00 & 0.86 & 0.22 & 0.03 & 1.00 & 0.22 & 0.00 & 0.00 \\
\hline 0.91 & 0.03 & 0.21 & 0.00 & 0.00 & 0.00 & 0.00 & 0.00 \\
\hline 0.00 & 0.00 & 0.00 & 0.00 & 0.00 & 0.00 & 0.00 & 0.00 \\
\hline 0.00 & 0.00 & 0.00 & 0.00 & 0.72 & 0.00 & 0.00 & 0.00 \\
\hline 0.15 & 0.01 & 0.00 & 0.00 & 0.00 & 0.00 & 0.00 & 0.03 \\
\hline 0.01 & 0.00 & 0.00 & 0.00 & 0.00 & 0.00 & 0.00 & 0.00 \\
\hline
\end{tabular}

Table 4 Fuzzy Information Matrix $\mathrm{X}_{\mathrm{OM}}$

\begin{tabular}{|l|l|l|l|l|l|}
\hline 0.00 & 0.00 & 0.00 & 0.00 & 1.00 & 0.00 \\
\hline
\end{tabular}

Table 5 Possibility Distribution $\mathrm{Y}_{\mathrm{ML}}$

\begin{tabular}{|l|l|l|l|l|l|l|l|}
\hline 0.03 & 1.00 & 0.08 & 0.30 & 0.42 & 0.38 & 0.67 & 0.07 \\
\hline 0.01 & 0.00 & 0.00 & 0.00 & 0.00 & 0.00 & 0.00 & 0.00 \\
\hline
\end{tabular}

Table 6 Dangerous Slope Prediction in TianShui

\begin{tabular}{cccc}
\hline Number & $\begin{array}{c}\text { Seismic } \\
\text { Landslide } \\
\text { Distance(m) }\end{array}$ & Number & $\begin{array}{c}\text { Seismic } \\
\text { Landslide } \\
\text { Distance(m) }\end{array}$ \\
\hline QZ-1 & 42.38 & MJ-2 & 75.85 \\
QZ-2 & 92.49 & MJ-3 & 27.18 \\
QZ-3 & 61.5 & MJ-4 & 109.7 \\
\hline
\end{tabular}

\begin{tabular}{cccc}
\hline QZ-4 & 134.56 & MJ-5 & 46.78 \\
QZ-5 & 87.41 & MJ-6 & 27.68 \\
QZ-6 & 165.78 & MJ-7 & 90.61 \\
QZ-7 & 121.6 & MJ-8 & 75.83 \\
QZ-8 & 42.78 & MJ-9 & 37.82 \\
QZ-9 & 43.61 & MJ-ST-1 & 29.12 \\
QZ-10 & 155.7 & MJ-ST-2 & 33.51 \\
MJ-1 & 68.92 & MJ-ST-3 & 23.12 \\
\hline
\end{tabular}

\section{ERROR COMPARISON}

In order to compare the fuzzy information optimizing processing method error with other method error, a simple example was given. Tongwei earthquake (Ms=7.5) which killed about 40000 people have occurred in 1718. The data is given as follow. 10 landslides as data and 5 landslides are picked as samples to compare the error of distance prediction methods.

Table 7 Error comparison results

\begin{tabular}{ccccc}
\hline Num & $\begin{array}{c}\text { Relative } \\
\text { altitude }\end{array}$ & Intensity & $\begin{array}{c}\text { Slope } \\
\text { Angle }\end{array}$ & $\begin{array}{c}\text { Distance } \\
(\mathrm{m})\end{array}$ \\
\hline 1 & 185 & 9 & $18^{\circ}$ & 400 \\
\hline 2 & 70 & 9 & $25^{\circ}$ & 150 \\
3 & 110 & 8 & $20^{\circ}$ & 450 \\
4 & 100 & 9 & $28^{\circ}$ & 270 \\
5 & 85 & 8 & $28^{\circ}$ & 470 \\
6 & 180 & 8 & $23^{\circ}$ & 1000 \\
7 & 90 & 8 & $18^{\circ}$ & 370 \\
8 & 120 & 8 & $26^{\circ}$ & 340 \\
9 & 170 & 9 & $16^{\circ}$ & 770 \\
10 & 190 & 9 & $17^{\circ}$ & 840 \\
11 & 170 & 8 & $11^{\circ}$ & 1250 \\
12 & 210 & 7 & $47^{\circ}$ & 890 \\
13 & 170 & 9 & 19 & 550 \\
14 & 240 & 8 & $42^{\circ}$ & 780 \\
15 & 160 & 9 & $24^{\circ}$ & 650 \\
\hline
\end{tabular}

According to the formulas of the distance prediction above, the distance results are calculated:

Fuzzy information optimizing processing method result :

Lcalculate $=\{885.2,741.9,696.6,691.5,678.2\}$

Lreal $=\{1250,890,550,780,650\}$

Standard deviation is given to verify the accuracy of the method :

$$
\begin{aligned}
\sigma= & \sqrt{\frac{1}{5} \sum_{i=1}^{5}\left(L_{c}-L_{r}\right)^{2}} \\
& \sigma=192.42 . \\
& \text { Experiment Formula: } \\
\mathrm{L}= & 2 *(\mathrm{H} 1-\mathrm{H} 2) \\
\mathrm{L} & = \begin{cases}340,420,340,480,320\}:\end{cases}
\end{aligned}
$$


$\sigma=508.33$

Scheidegger Formula

$\mathrm{Lg}(\mathrm{H} / \mathrm{L})=\mathrm{algV}+\mathrm{b}$

$\mathrm{L}=\{173.58,228.11,208.09,252.65,182.47\}$

$\sigma=664.88$

Kokusho Formula :

$\mathrm{H} / \mathrm{L}=0.73 \tan \alpha-0.07$

$\mathrm{L}=\{2583.08, \quad 109.46,93.86,204.43,160.88\}$

$\sigma=795.94$

Then we compare the results with the real data in a diagram to find out which method is more accurate. It is shown that the result of fuzzy information optimizing processing method is more fitting than other methods on predicting the loess seismic landslides sliding distance.

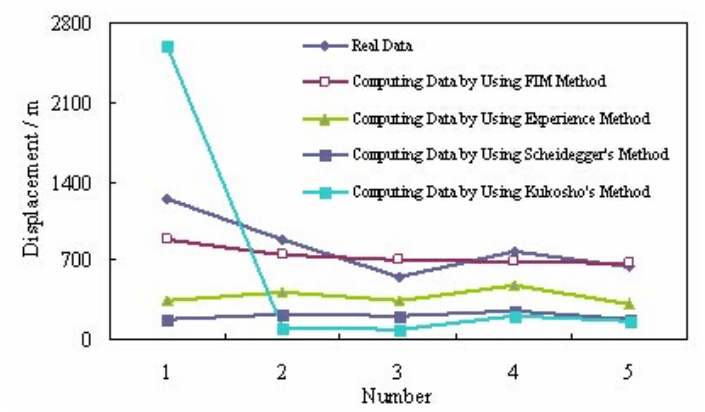

Fig.10 The comparison of different prediction method

\section{CONCLUSIONS}

The types of landslides in Loess Plateau area may be classified as loess landslides, loess-bedrock interface landslides, loess-bedrock landslides and loess-gravel-bedrock landslides. Among them, loess landslides are most common to be induced by earthquakes.

The seismic stability of 22 loess slopes based on the Morgan Stanley-Price method shown that the slopes along the valley of Tianshui City have hight risk of sliding. Under the effect of basic seismic intensity of VIII degree corresponding to a ground motion of $0.3 \mathrm{~g}$, most of slopes may loose their stability to slide down. The factors of influencing seismic stability of loess slopes are seismic intensity, slope angle, internal friction and cohesion, unit weight and water content.

The method of predicting sliding distance by means of fuzzy information model is more suitable for loess landslides induced by earthquakes. The predicted sliding distances of loess landslides in Tianshui city ranging from $23.12 \mathrm{~m}$ to $165.78 \mathrm{~m}$ warn the people to keep a safe distance for staying or constructing buildings away from the dangerous zone.

\section{ACKNOWLEDGEMENTS}

The authors would like to appreciate The National Foundation on Natural Science of China for the financial support to this study (Granted No.51478444,
$51408567)$

\section{REFERENCES}

1) Wang Lanmin, etc. (2003): Loess dynamics [M]. Beijing, Seismological Press,(In Chinese).

2) Lanzhou Institute of Seismology, SSB. (1985):Strong earthquake catalogue for Shanxi, Gansu, Ningxia and Qinghai[M]. Shanxi Science and Technology Press, China, 22 〜35 (In Chinese).

3) Wang Nianqin, Zhang Zhuoyuan, Wang Jiading. (2003): A forecasting method of sliding distance on typical loess landslides[J]. Journal of Northwest University (Natural Science Edition) 33(1) :111-114.

4) Nai Wang, Lanmin Wang, Zhongxia Yuan. (2012) : Characteristic and stability analysis for loess seismic landslide in valley city. Advances in Industrial and Civil Engineering. 594-597pp:1856-1863

5) Chen Yongming, Shi Yucheng, Liu Hongmei,etc.(2005), Distribution of characteristics and influencing factors analysis of seismic loess landslide[J]. Earthquake in China. 21(2) :235-243.

6) Cheng Yongming, Shi Yucheng.(2006), Basic characteristics of seismic landslides in loess area of Northwest China [J]. Journal of seismological research. 29(3): 276-280 (In Chinese).

7) Wang Nai, Wang Lanmin. Characteristic and influencing factors analysis of seismic loess slope in the valley area [J]. (2013): Chinese Journal of Geotechnical Engineering,,S1: 434-438.

8) W.Weijiang, W.Nianqin. (2006): Landslide disaster in Gansu[M]. Lanzhou University Press, China .

9) Liu Yue,Huang Qianbin. (2001): A forecast pattern of the side distance of loess landslides [J]. Journal of Catastrophology, 16 (3): 7-12. 